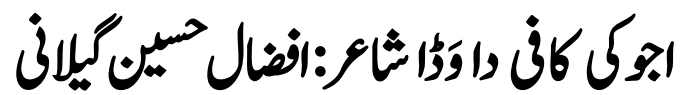

\section{The Great Poet of Today's Kafi: Afzal Hussain Gilani}

\section{Zaitoon Fatma}

M.Phil. Scholar, Department of Urdu, Riphah International University, Faisalabad Campus, Pakistan Saadia Imtiaz

M.Phil. Scholar, Department of Urdu, University of Sialkot, Sialkot, Pakistan

\section{KE YWOR D S}

\section{Kafi}

Biography

Sufism

Beloved

\section{A T E S}

Received 10-07-2021

Accepted 5-09-2021

Published 19-09-2021

\section{A B S T R A C T}

Kafi is a genre of Poetry that is found in the poetry of Sufis. It contains accessories such as Naat, Manqabat, and Qasida where the state of distance and the pleasure of connection are maintained. Kafi began with Shah Hussain and many Sufi poets experimented with it. One of them is Syed Afzal Hussain Gilani who has described Kafi as a classical tradition as well as a contemporary one. This article discusses Syed Afzal Hussain Gilani's Kafies.

DOI: https://doi.org/10.54064/negotiations.v1i2.20

Q R C O D E

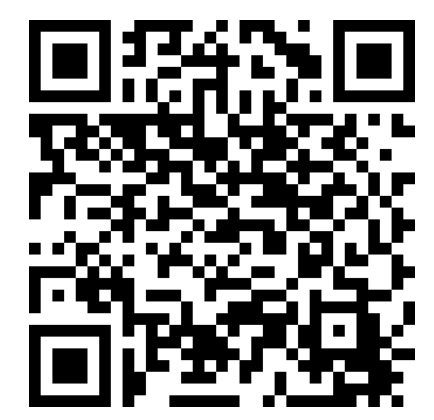

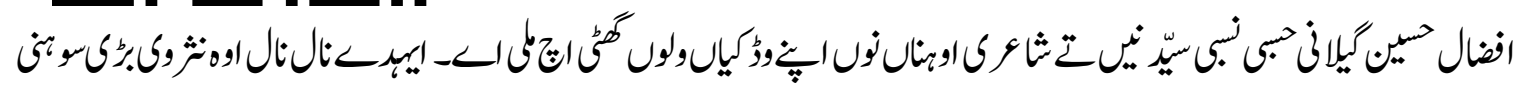

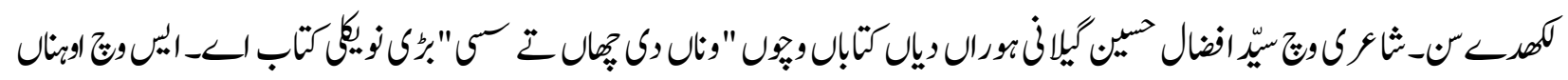

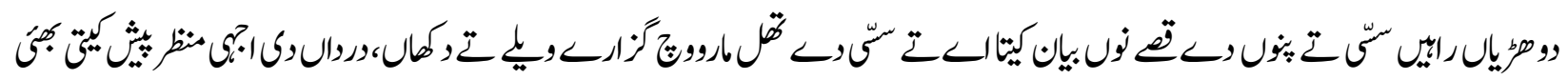

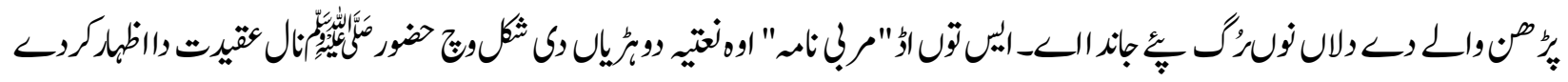

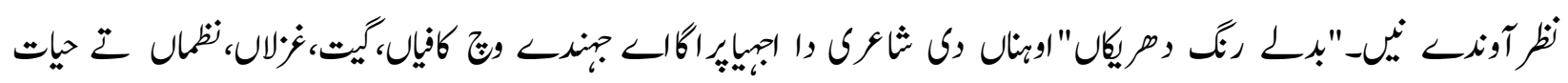




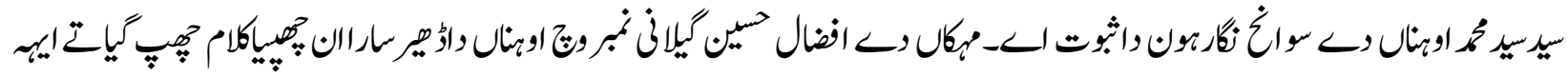

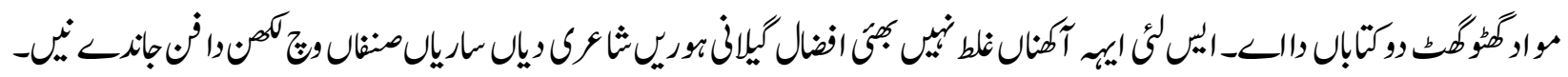

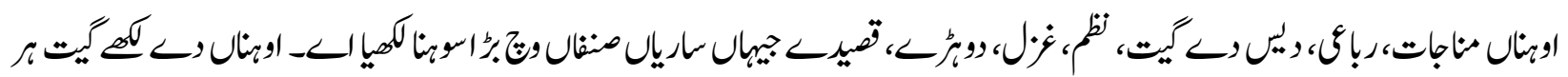

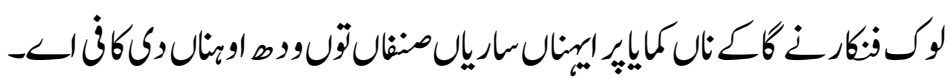

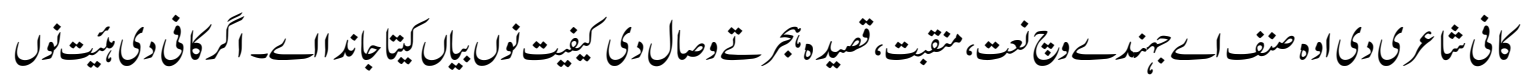

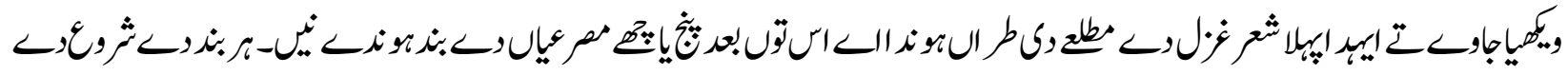

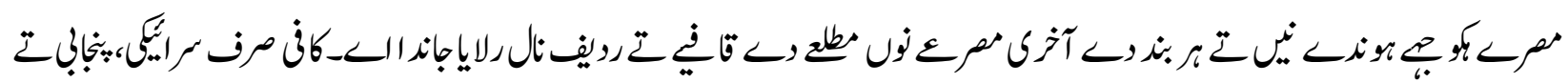

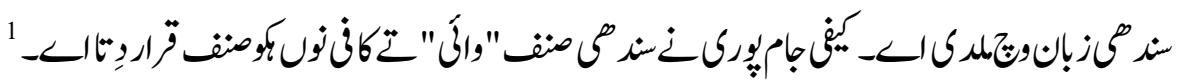

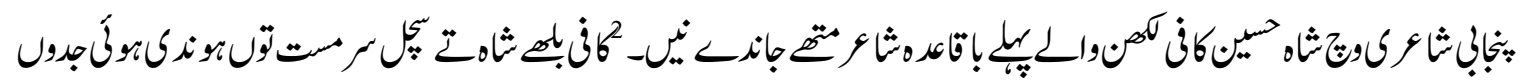

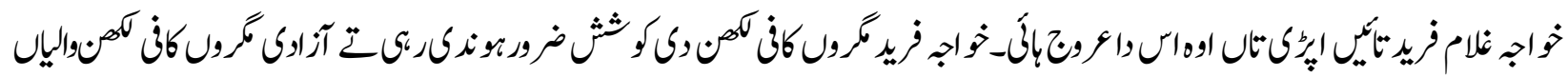

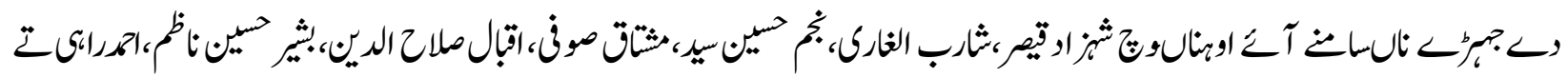

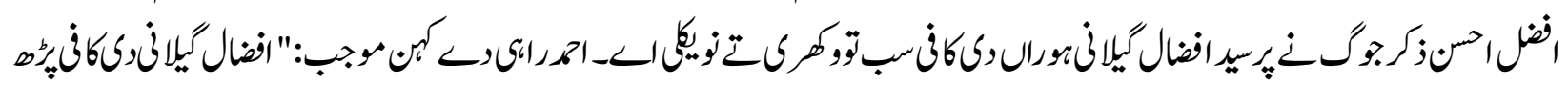

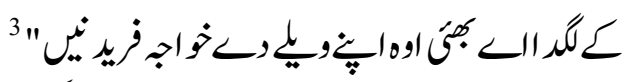

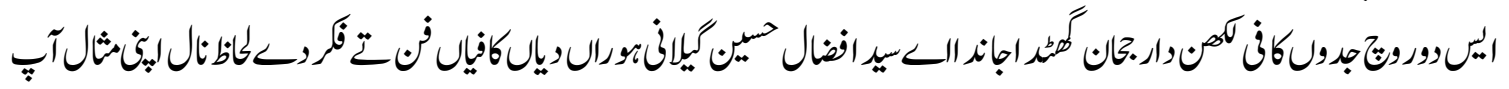

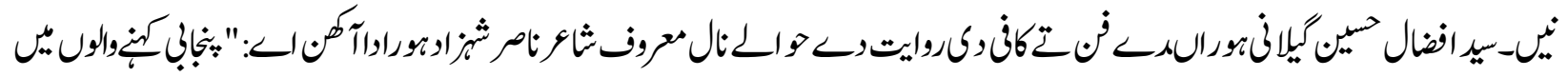

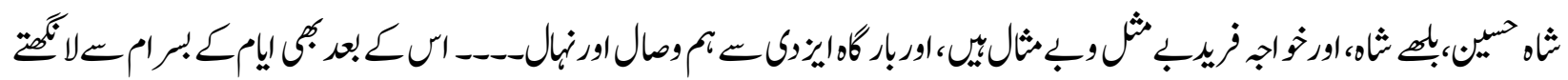

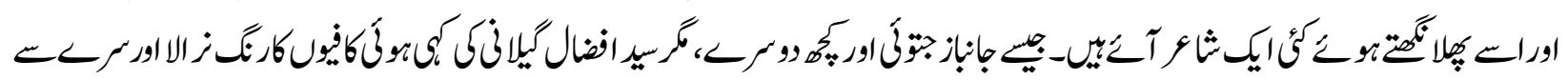

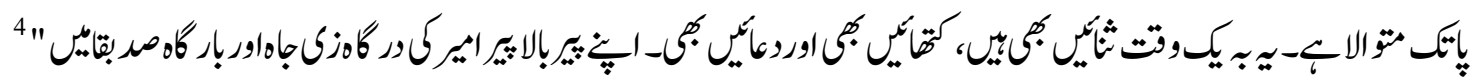

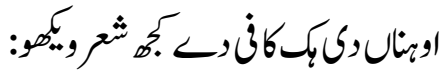

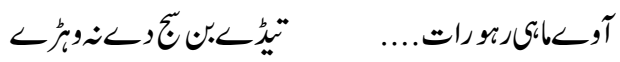

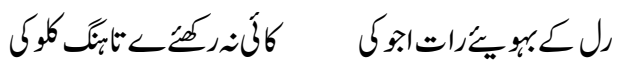

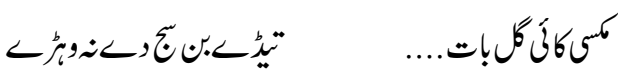

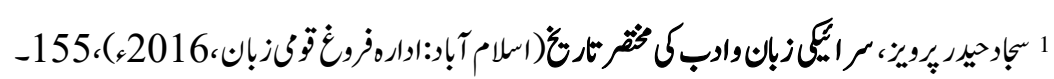

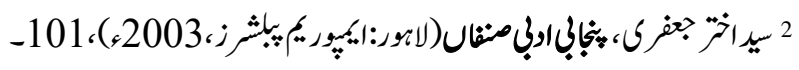

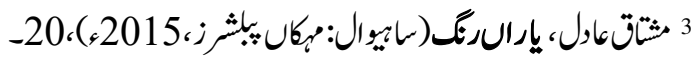

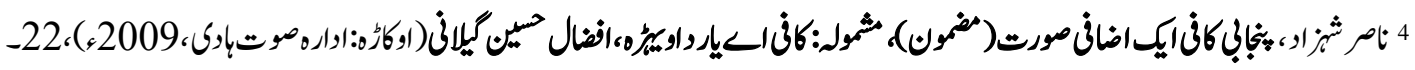




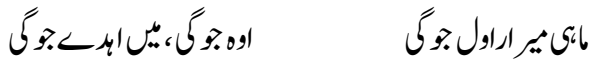

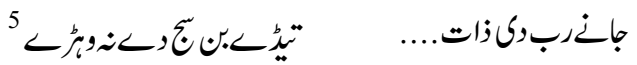

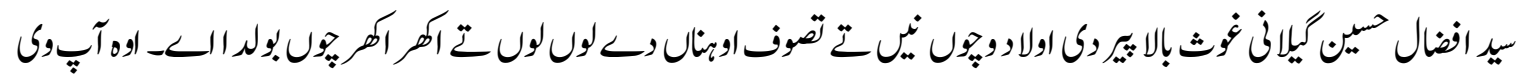

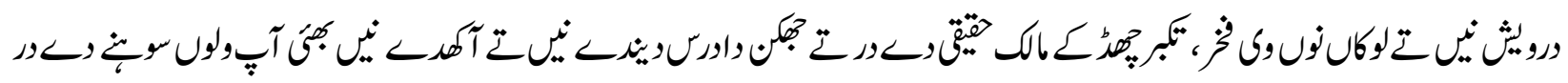

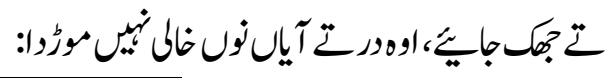

\begin{tabular}{|c|c|}
\hline بن وَنُمر رمولاًُ & 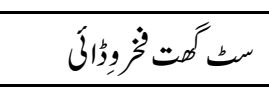 \\
\hline 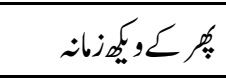 & 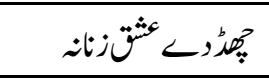 \\
\hline بت ثقنى ارائى & ن لفئر \\
\hline 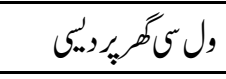 & مولا يُ كرئ! \\
\hline 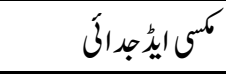 & 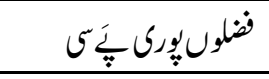 \\
\hline ونه & 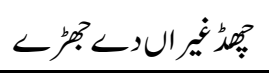 \\
\hline 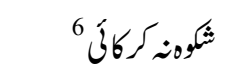 & $<$ \\
\hline
\end{tabular}

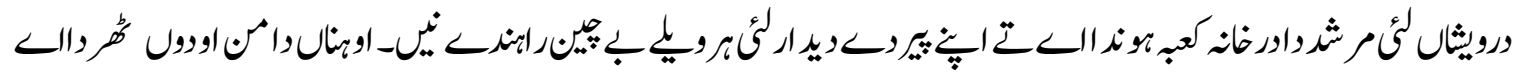

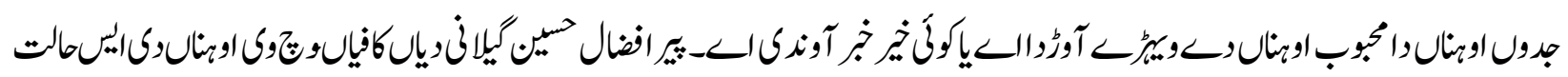

\begin{tabular}{|c|c|}
\hline 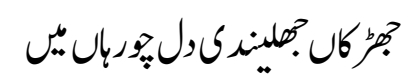 & مجبورتون"يُ، مجبوربالي \\
\hline ولر اتالَّلو، آوالن آوال & وسر ان كؤَ، كيولوروباليّ؟ \\
\hline آهُار مبوس، آونوطنوس & 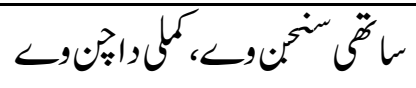 \\
\hline 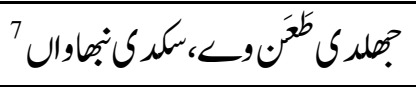 & 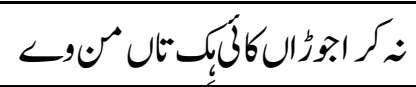 \\
\hline
\end{tabular}

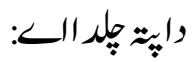

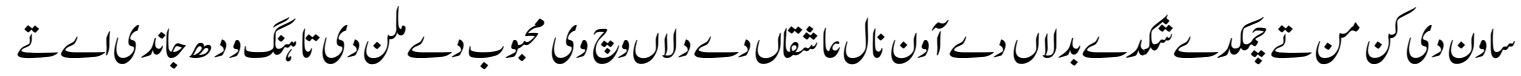

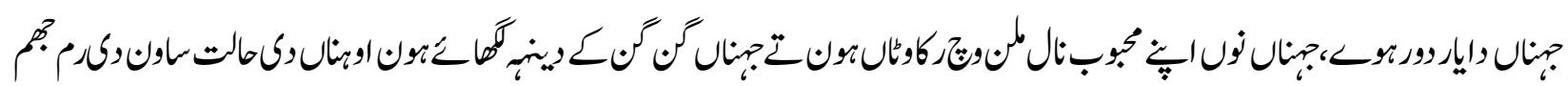

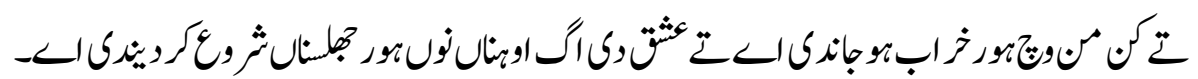

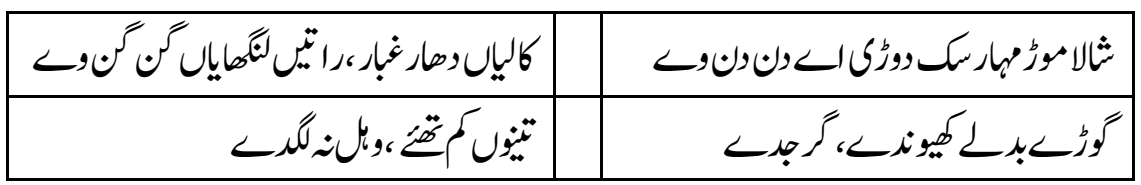

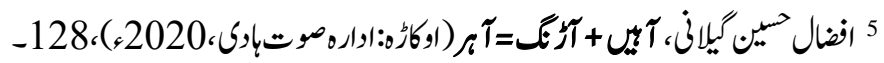
129، إينأن

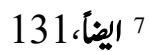




\begin{tabular}{|c|c|}
\hline 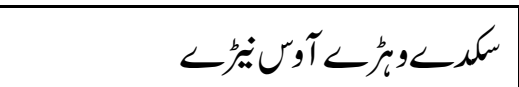 & 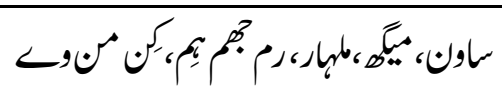 \\
\hline 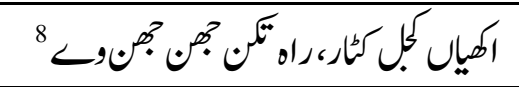 & 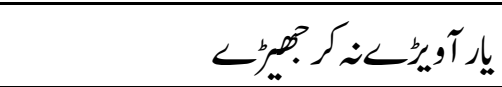 \\
\hline
\end{tabular}

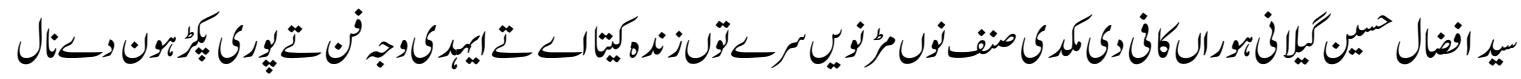

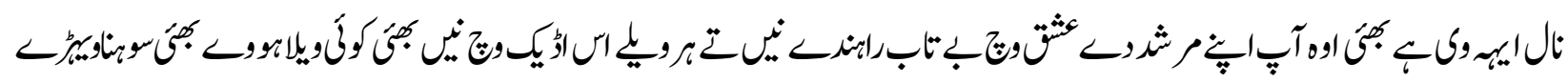
آورُّح:

\begin{tabular}{|c|c|}
\hline 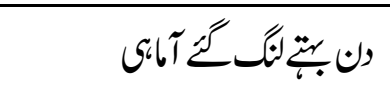 & رترونرك كوكلالانى \\
\hline 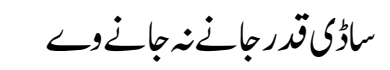 & ثالاينالاخثيالمانـــ \\
\hline ثالانوكَّدرخدابانى & ويواسومرمنال,وعابايى \\
\hline كوكال لميال كركبابالوـ & 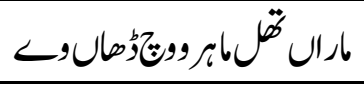 \\
\hline راه هتمركى كوبسجابانى & 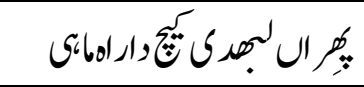 \\
\hline جِيَّالمر تساريال ليكالوـ & 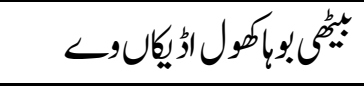 \\
\hline 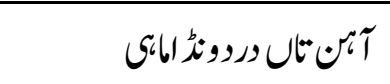 & 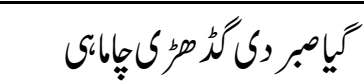 \\
\hline
\end{tabular}

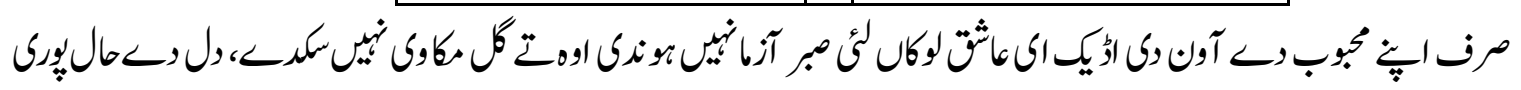

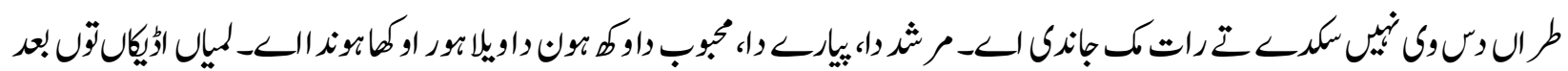

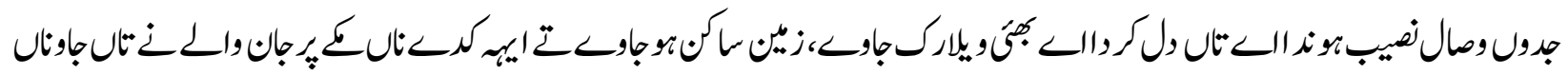

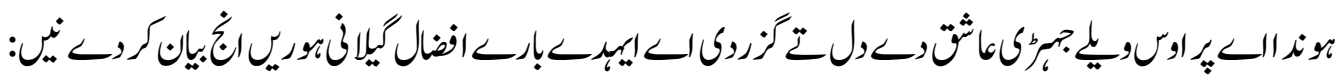

\begin{tabular}{|c|c|}
\hline 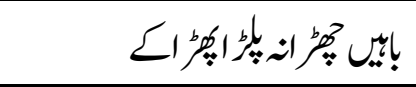 & 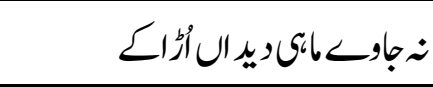 \\
\hline نوكيال تير ابوب تولٍِـ--نال & 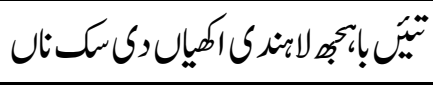 \\
\hline اكسيانج ان: اكميالتولاك & 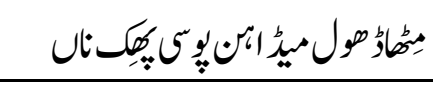 \\
\hline 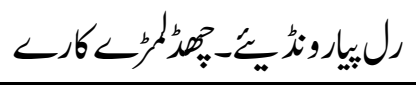 & 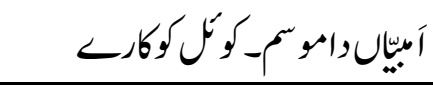 \\
\hline 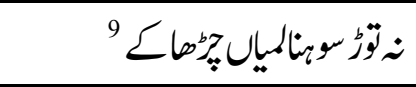 & 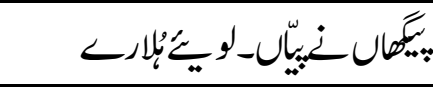 \\
\hline
\end{tabular}

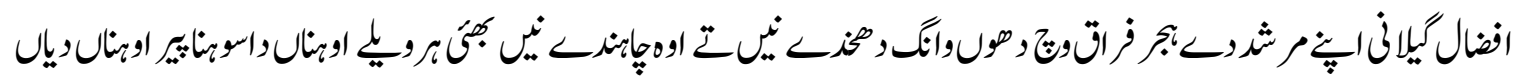

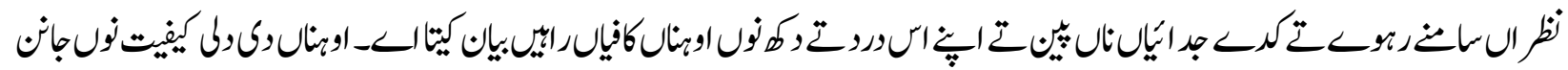

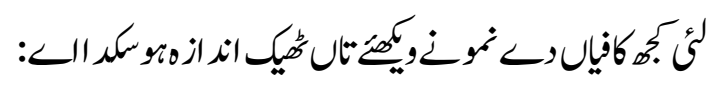




\begin{tabular}{|c|c|}
\hline 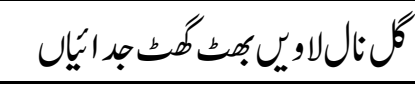 & آلوسعانى كرجارَسايِّاِ \\
\hline 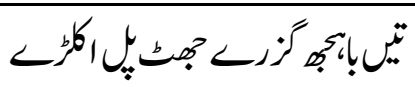 & 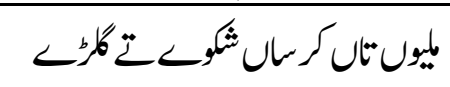 \\
\hline 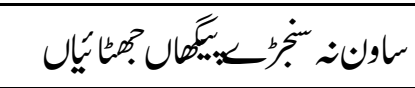 & 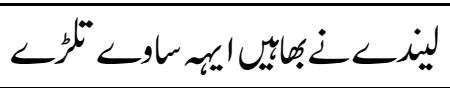 \\
\hline 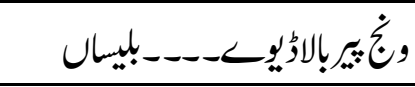 & 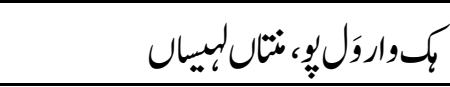 \\
\hline 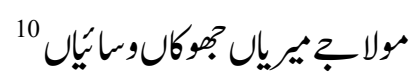 & 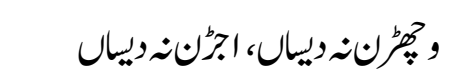 \\
\hline
\end{tabular}

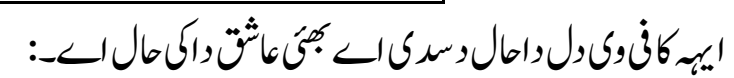

\begin{tabular}{|c|c|}
\hline 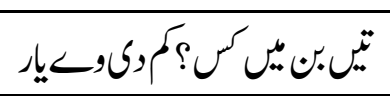 & 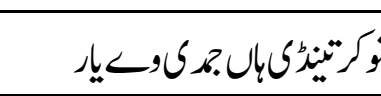 \\
\hline نزانكر،ن غزركيان & 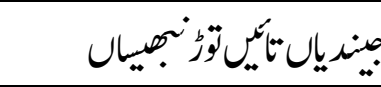 \\
\hline 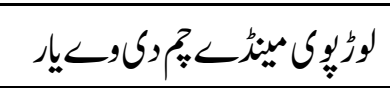 & 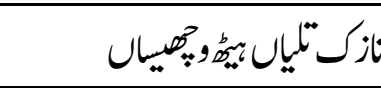 \\
\hline 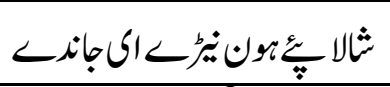 & 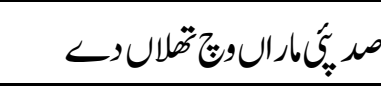 \\
\hline 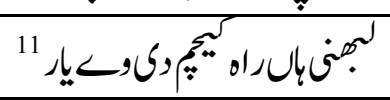 & 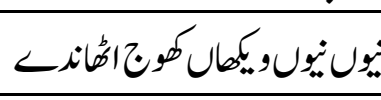 \\
\hline
\end{tabular}

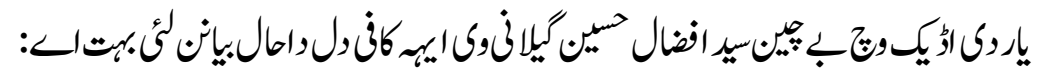

\begin{tabular}{|c|c|}
\hline 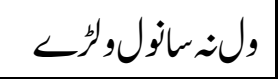 & 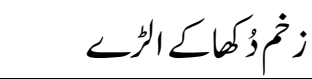 \\
\hline نئر & 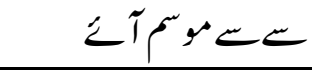 \\
\hline ولنه سانولورُ & تت سنيرط كملط ح \\
\hline 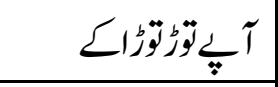 & آي يايركلاك \\
\hline ولنه سانولورلما & 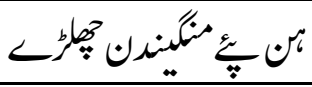 \\
\hline 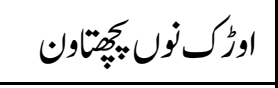 & 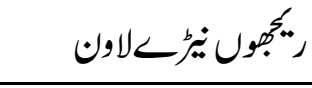 \\
\hline 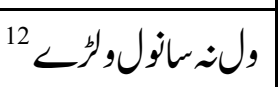 & رولن ار، ثتملطيك \\
\hline
\end{tabular}

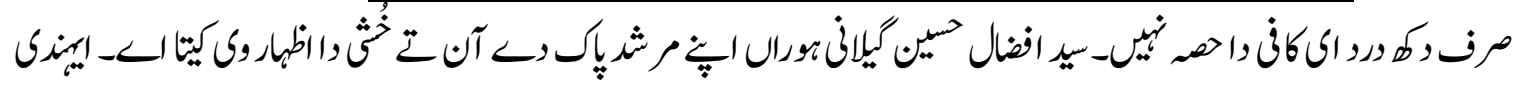

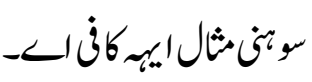

\begin{tabular}{|c|c|}
\hline 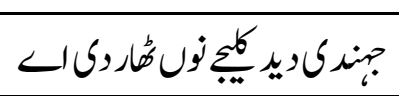 & آويكموظ| يه كون آيا \\
\hline 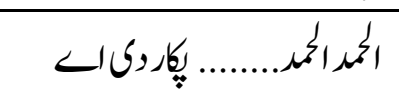 & 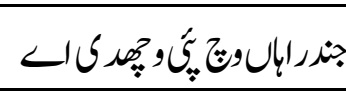 \\
\hline
\end{tabular}




\begin{tabular}{|c|c|c|}
\hline & 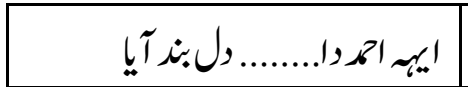 & سانولير حيّ.....يندرآيا \\
\hline & ككانونسكوي اروكاس & 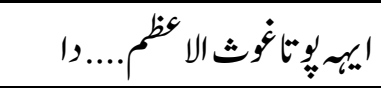 \\
\hline & 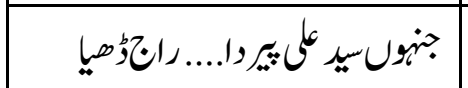 & كوكَوسرانيّليركنيرجيها \\
\hline & جنر آبِ & خلقت اوبيركويو انظاسـ... \\
\hline \multicolumn{3}{|c|}{ 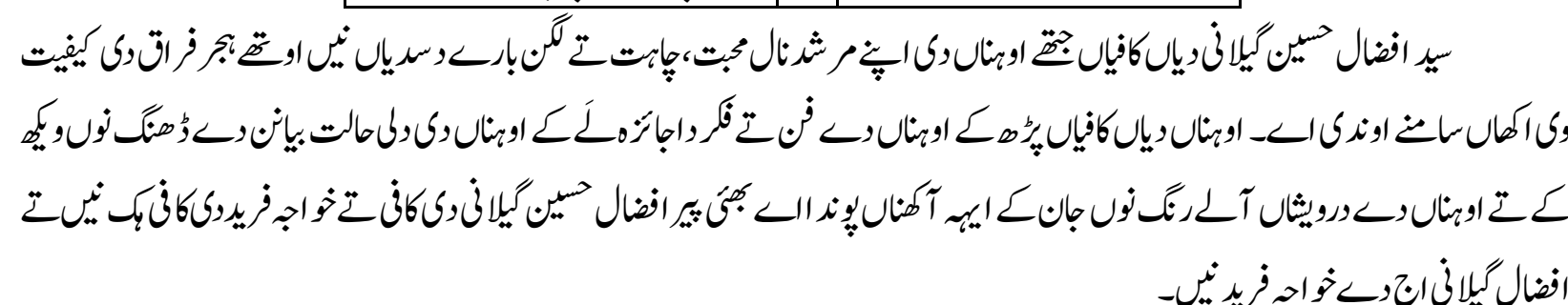 } \\
\hline
\end{tabular}

象金方 